\title{
Rancang Bangun Gyroscope Stabilizer untuk Stabilisasi Perahu
}

\author{
Deri Teguh Santoso ${ }^{*}$, Rianita Puspa Sari ${ }^{2}$, Fahad Fadlillaahi Mudzakir ${ }^{1}$ \\ ${ }^{1}$ Program Studi S1 Teknik Mesin, Universitas Singaperbangsa Karawang \\ 2 Program Studi S1 Teknik Industri, Universitas Singaperbangsa Karawang \\ Jl. H.S. Ronggowaluyo Telukjambe Timur, Karawang \\ *E-mail: deri.teguh@ft.unsika.ac.id
}

Diterima: 21-11-2020; Direvisi: 10-03-2021; Dipublikasi: 27-04-2021

\begin{abstract}
Abstrak
Penggunaan perahu sering terjadi banyak insiden kecelakaan yang disebabkan oleh cuaca, ombak yang tinggi, maupun perahu yang tidak memenuhi standar keselamatan. Mengurangi jumlah kecelakaan pada perahu melalui meminimalkan sudut kemiringan pada perahu yang disebabkan oleh ombak. Solusi yang ditawarkan adalah penambahan komponen berupa gyroscope stabilizer yang berfungsi untuk menstabilkan sudut kemiringan akibat gelombang yang bergulung. Metode ini dibagi menjadi 2 tahap utama yaitu perancangan fisik-elektronika, dan pengujian menggunakan faktorial lengkap. Pengujian menggunakan variabel dependent berupa sudut kemiringan perahu, sedangkan variabel independent berupa tinggi ombak yang diuji dan kecepatan flywheel dari gyroscope stabilizer yang diaplikasikan dengan masing-masing tiga level dan tiga pengulangan. Hasil pengujian dilakukan analisis variansi dengan hasil yang dicapai yaitu tingkat kemiringan terbesar pada kecepatan flywheel $0 \mathrm{rpm}$, dengan tinggi gelombang $10 \mathrm{~cm}$ menghasilkan sudut kemiringan 3-4 derajat. sedangkan variasi parameter yang sesuai untuk menstabilkan perahu yaitu 2500 rpm dengan rentang sudut kemiringan perahu yang dihasilkan antara 0,55-1 derajat kemiringan. Kesimpulannya adalah semakin tinggi ombak membutuhkan semakin tinggi kecepatan flywheel sehingga semakin kecil sudut kemiringan perahu yang dihasilkan, namun apabila terlalu tinggi kecepatan flywheel mengakibatkan tidak optimal kinerja gyroscope stabilizer. Menggunakan alat ini memberikan efektivitas yang baik sebagai penstabil perahu dengan sudut kemiringan menjadi 1,6 derajat jika dibandingkan tanpa gyroscope stabilizer yaitu kemiringan 5,4 derajat.
\end{abstract}

Kata kunci: gyroscope stabilizer; ombak; perahu.

\begin{abstract}
The use of boats often occurs with many accidents caused by weather, high waves, or boats that do not meet safety standards. Reducing the number of accidents on the boat by minimizing the tilt angle on the boat caused by waves. The solution offered is adding a component in the form of a gyroscope stabilizer which functions to stabilize the angle of tilt caused by rolling waves. The method is divided into 2 main steps, there are physical-electronic design, and testing using full factorial. Testing using the dependent variable is tilt angle of the boat, while the independent variable are the height of the waves and the speed of flywheel of the gyroscope stabilizer which is applied with three levels and three repetitions respectively. The test results were analyzed use ANOVA with the results achieved, namely the highest tilt angle at a flywheel speed of $0 \mathrm{rpm}$, with a wave height of $10 \mathrm{~cm}$ resulting in a 3-4 degree tilt angle. While the variation of the parameters suitable for stabilizing the boat is $2500 \mathrm{rpm}$ with the resulting boat tilt angle range between 0.55-1 degrees of tilt. The conclusion is that the higher the waves require the higher the flywheel speed so that the smaller the resulting tilt angle of the boat, However, if the flywheel speed is too high, the gyroscope stabilizers performance is not optimal. Using this device provides good effectiveness as a boat stabilizer with a tilt angle of 1.6 degrees when compared without a gyroscope stabilizer, which is a tilt angle of 5.4 degrees.
\end{abstract}

Keywords: boat; gyroscope stabilizer; wave.

\section{Pendahuluan}

Sektor perkapalan pada tahun ini masih mengalami impak akibat dari krisis global yang di bidang industri maritim, sehingga berdampak pada tersendatnya inovasi di bidang teknologi perkapalan [1]. Transportasi air saat ini masih kurang diperhatikan terutama terkait dengan faktor keselamatan dan kenyamanan. Jenis kecelakaan yang terjadi pada kapal diantaranya dapat berupa tenggelam, kandas, tabrakan, kebakaran dan lainnya. Sedangkan penyebab kecelakaan kapal 
diantaranya 78,45\% human error, 10,75\% faktor cuaca, 9,67\% faktor kesalahan teknis, dan faktor lainnya [2]. Hal ini menunjukkan masih kurangnya perhatian khusus terhadap transportasi air, terutama dari segi penerapan teknologi.

Beberapa kejadian yang kecelakaan yang terjadi diantaranya terjadi sebanyak 191 kasus pada periode 1998-2002, tahun 2006 terdapat 6 kasus kapal yang mengalami terbalik dan tenggelam [2] dan insiden korban 21 orang tenggelam diantaranya 6 orang meninggal pada 22 Desember 2017 di waduk cirata, Jawa Barat [3] diakibatkan cuaca sedang buruk menimbulkan ombak besar yang menyebabkan perahu terbalik. Beberapa kasus tersebut menunjukkan bahwa pentingnya solusi keselamatan pada transportasi air dalam segi penerapan teknologi.

Beberapa penerapan teknologi pada transportasi air yang telah dilakukan oleh peneliti lain, diantaranya modifikasi badan perahu untuk menggunakan fiberglass [4], penggunaan panel surya pada perahu [5], generator listrik independent [6], robot perahu pembersih sampah [7], sistem informasi perahu berbasis lokasi [8], pemanfaatan energi angin dan surya [9] dan motor penggerak perahu bertenaga surya [10]. Diantara contoh tersebut masih didominasi oleh penerapan teknologi untuk sumber tenaga listrik, dan masih kurang teknologi dalam aspek keselamatan pada perahu.

Solusi yang ditawarkan yaitu penerapan teknologi pada perahu menggunakan gyroscope stabilizer yang berfungsi untuk menstabilkan kemiringan perahu yang diakibatkan oleh gulungan/rol ombak. Penggunaan gyroscope stabilizer ini mengacu pada paten yang telah ada sejak 1917 [11]. Namun beberapa perkembangan menggunakan mekanisme gyroscope stabilizer masih minim diterapkan pada perahu. Beberapa diantaranya diterapkan pada mekanisme panahan [12], pada turbin angin [13], dan pada senjata api [14].

\section{Material dan metodologi}

Penerapan gyroscope stabilizer pada perahu pada dasarnya dapat diterapkan pada semua jenis perahu, dengan penyesuaian pada ukuran perahu dan dimensi gyroscope stabilizer. Semakin besar ukuran perahu yang digunakan maka memerlukan perbandingan gyroscope stabilizer yang lebih besar serta daya motor yang lebih tinggi, walaupun memerlukan pendalaman kecocokan antara perahu dan gyroscope stabilizer yang digunakan.

Pada penelitian kali ini menggunakan prototype perahu jenis perahu sampan yang biasa digunakan pada sungai kecil atau danau. Perahu jenis sampan ini biasanya memiliki Panjang hingga 4 meter, dengan penumpang hingga 6 orang. Prototype perahu sampan ini dengan penyesuaian skala 1:10, dengan spesifikasi prototype dapat dilihat pada Tabel 1. Konsep metodologi yang digunakan pada alat gyroscope stabilizer ini dibagi menjadi dua kelompok besar yaitu perancangan physical dan electronic.

Tabel 1. Spesifikasi prototype perahu

\begin{tabular}{cc}
\hline Item & Deskripsi \\
\hline Skala dengan sebenarnya & $1: 10$ \\
Panjang & $40 \mathrm{~cm}$ \\
Lebar & $20 \mathrm{~cm}$ \\
Tinggi & $15 \mathrm{~cm}$ \\
Material & Multipleks dan Tyrofoam \\
Hardener & Resin \\
\hline
\end{tabular}

\subsection{Perancangan physical dan electronic}

Perancangan physical yang dimaksud diantaranya mencangkup perancangan rangka perahu yang menggunakan bahan akrilik, flywheel sebagai penghasil gaya gyroscopic, rangka/mounting flywheel yang bergerak secara translasi dan digerakan oleh motor servo, dan bantalan bearing sebagai peredam gesekan. Perancangan electronic yang dimaksud 
Deri teguh Santoso dkk /Jurnal Rekayasa Mesin

p-ISSN: 1411-6863, e-ISSN: 2540-7678

Vol.16|No.1|62-68|April|2021

mencangkup motor DC yang berfungsi memberikan daya putar pada flywheel, microcontroller Arduino uno, sensor kemiringan menggunakan jenis MPU6050, panel box untuk pembagi daya dan arus listrik, dan baterai 12V 5A. Di dalam perancangan electronic menggunakan skematik rangkaian yang tersambung dengan komponen physical dapat dilihat pada Gambar 1.

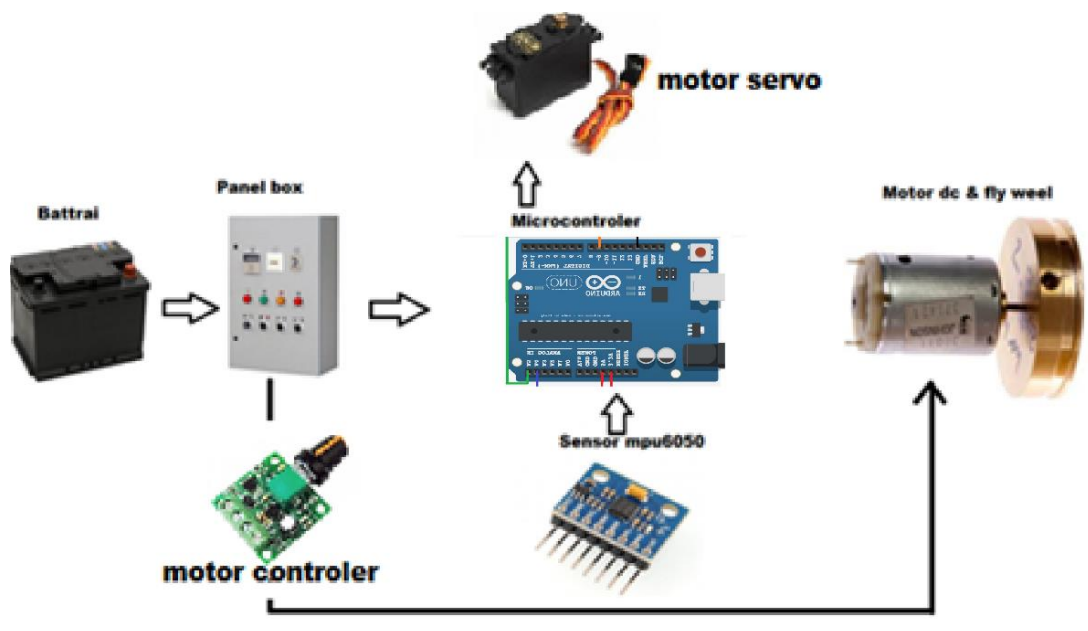

Gambar 1. Skematik rangkaian pada gyroscope stabilizer

Pada Gambar 1 memperlihatkan skematik rangkaian dari alat gyroscope stabilizer. Sumber daya 12V Dari baterai diteruskan ke panel box dan dari panel box daya di bagikan ke microcontroller arduino uno, motor servo dan flywheel. Microcontroler arduino uno berfungsi sebagai pengolah data dari sensor gyroscope MPU6050, berupa data kemiringan yang akan diubah oleh microcontroler arduino uno menjadi sinyal gerak ke motor servo. Motor servo berfungsi memutarkan flywheel yang diatur oleh motor. Flywheel apabila diubah kemiringannya secara translasi rotasi akan menghasilkan gaya gyroscopic. Kemiringan flywheel akan diatur oleh motor stepper sesuai perintah microcontroler arduino uno

\subsection{Perancangan alat gyroscope stabilizer}

Perancangan desain alat pada gyroscope stabilizer ini menggunakan software inventor 2015. Pada desain ini tercantum komponen yang terpasang langsung, dan dapat dilihat pada Gambar 2.

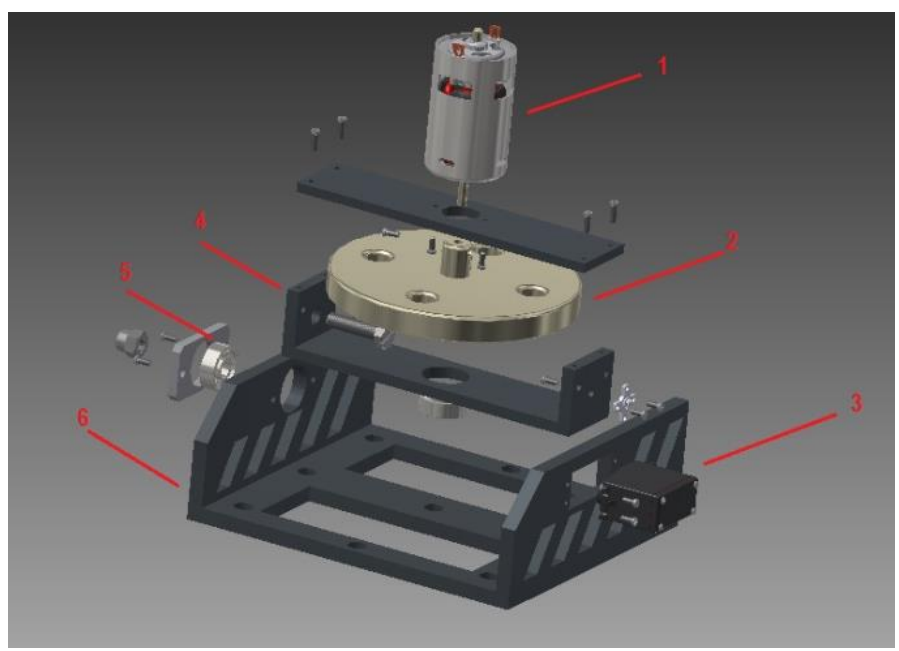

Gambar 2. Komponen utama pada gyroscope stabilizer 
Keterangan gambar sesuai dengan nomor yaitu: 1) Motor DC, 2) flywheel, 3) motor servo, 4) mounting flywheel, 5) bearing, 6) rangka gyroscope. Ukuran rangka Gyroscope Stabilizer mempunyai lebar 1/2 dari lebar perahu, panjang 1/3 dari panjang perahu dan ukuran ini menyesuaikan dari perahu prototype yang sudah ada. Spesifikasi ukuran perahu yaitu memiliki tinggi $15 \mathrm{~cm}$, Panjang $100 \mathrm{~cm}$, dan lebar $40 \mathrm{~cm}$. Flywheel yang digunakan memiliki ukuran diameter $8 \mathrm{~cm}$ dan tebal $6 \mathrm{~cm}$ serta terbuat dari material baja anti karat dengan lapisan chrome.

\subsection{Sistem kendali pada microcontroller arduino uno}

Pada arduino uno memiliki fasilitas untuk komunikasi dengan komputer atau berkomunikasi dengan arduino lainnya. Chip Atmega328 menyediakan komunikasi serial UART TTL (5V) yang tersedia di pin 0 (RX) dan pin 1 (TX). Sebuah chip FTDI yang terdapat pada board berfungsi menerjemahkan bentuk komunikasi ini. Melalui USB akan tampil sebagai virtual port di komputer. Pada Arduino Software (IDE) terdapat monitor serial yang memudahkan data textual untuk dikirim menuju arduino atau keluar dari arduino seperti gambar di bawah. Terdapat Lampu led TX dan RX yang akan menyala berkedip-kedip ketika ada data yang ditransmisikan melalui chip FTDI USB to Serial via kabel USB ke komputer. Komunikasi serial dari digital pin menggunakan Software Serial library.

\subsection{Pengaturan gerak motor stepper dan flywheel}

Adanya gaya gyroscopic pada alat ini, flywheel yang berputar harus digerakan secara translasi rotasi ke depan dan ke belakang. Gerak translasi pada flywheel digerakan oleh motor stepper yang bergerak sesuai perintah microcontroler, perintah-perintah yang berasal dari sensor kemiringan MPU5060 yang ditempatkan di dasar lambung perahu seperti Gambar 3 di bawah ini. Sensor MPU5060 berfungsi membaca kemiringan perahu dari gerakan rol ombak di sekitarnya.
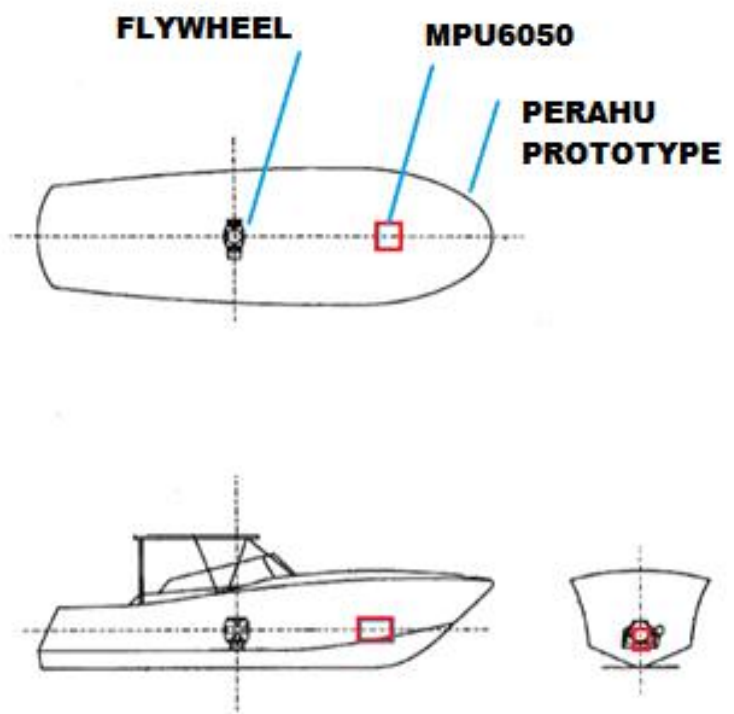

Gambar 3. Lokasi penempatan sensor dan gyroscope stabilizer

\subsection{Variabel yang diujikan}

Alat Gyroscope stabilizer dilakukan pengujian menggunakan variabel dependent yaitu sudut kemiringan dari perahu yang dilakukan beberapa pengulangan sehingga ditemukan nilai min, maks dan rerata nya. Sedangkan variabel independent berupa kecepatan putaran flywheel (rpm), dan ketinggian ombak. Seperti yang terlihat pada tabel 2 di bawah ini. 
Tabel 2. Variabel Pengujian

\begin{tabular}{|c|c|c|c|c|c|}
\hline No. & Kecepatan flywheel & Tinggi ombak & \multicolumn{3}{|c|}{ Sudut kemiringan kapal } \\
\hline 1. & & $3 \mathrm{~cm}$ & \multirow{9}{*}{$\begin{array}{c}\text { Nilai } \\
\text { Minimal }\end{array}$} & \multirow{9}{*}{$\begin{array}{c}\text { Nilai } \\
\text { Maksimal }\end{array}$} & \multirow{9}{*}{$\begin{array}{c}\text { Nilai } \\
\text { Rerata }\end{array}$} \\
\hline 2. & $0 \mathrm{rpm}$ & $5 \mathrm{~cm}$ & & & \\
\hline 3. & & $10 \mathrm{~cm}$ & & & \\
\hline 4. & & $3 \mathrm{~cm}$ & & & \\
\hline 5. & $2500 \mathrm{rpm}$ & $5 \mathrm{~cm}$ & & & \\
\hline 6 & & $10 \mathrm{~cm}$ & & & \\
\hline 7 & & $3 \mathrm{~cm}$ & & & \\
\hline 8 & $5000 \mathrm{rpm}$ & $5 \mathrm{~cm}$ & & & \\
\hline 9 & & $10 \mathrm{~cm}$ & & & \\
\hline
\end{tabular}

\section{Hasil dan pembahasan}

Pengujian keseluruhan bertujuan untuk mengetahui kinerja dari perangkat keras dan perangkat lunak untuk menghasilkan data yang diinginkan. Pengujian keseluruhan sistem meliputi pengujian keseimbangan perahu terhadap ombak yang diberikan. Pengujian dilakukan dengan mengambil 20 sampel kemiringan perahu dalam 60 detik lalu di rataratakan.

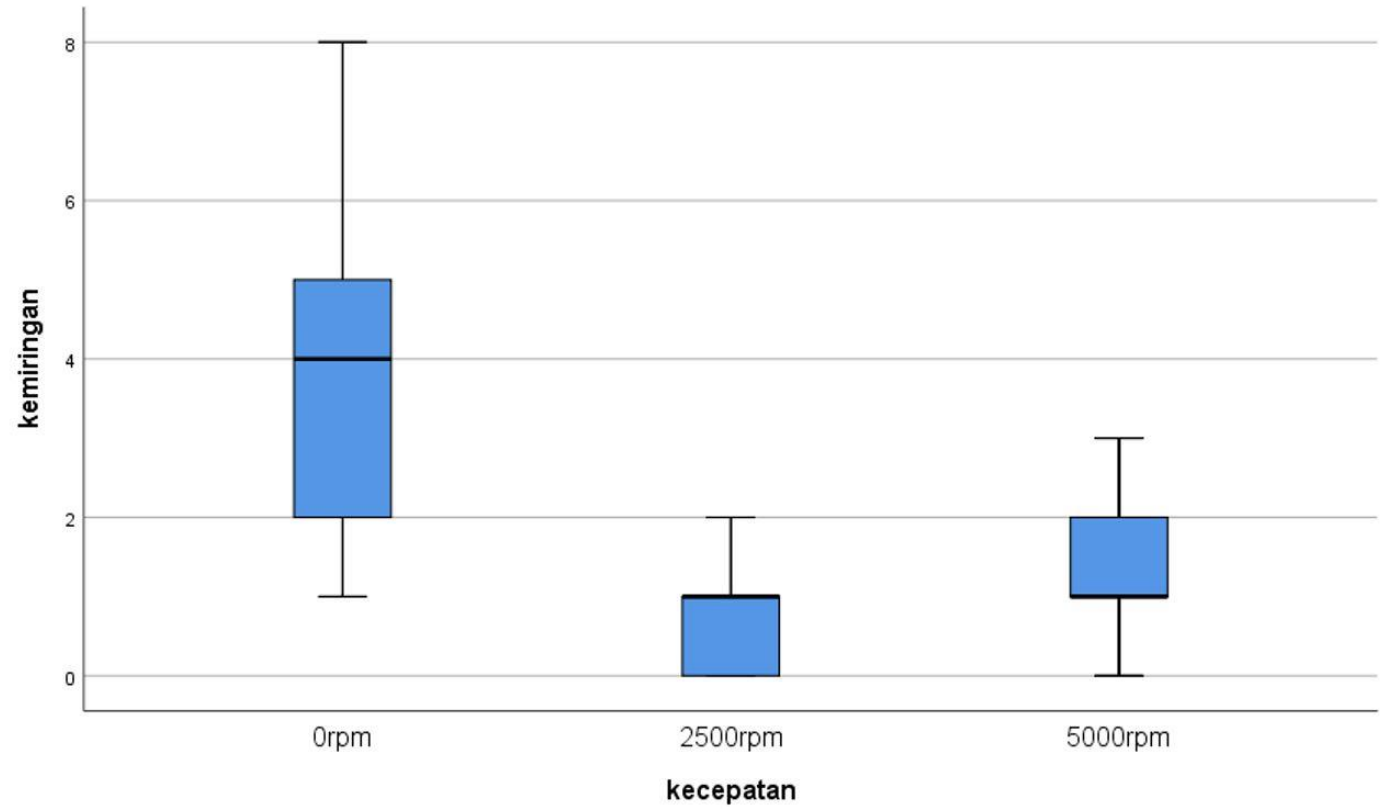

Gambar 4. Grafik hasil pengujian dengan kriteria min, maks, dan rerata

Gambar 4 menunjukkan hasil pengujian berupa sudut kemiringan perahu dengan kriteria min, maks, dan rerata. Hasil pada gambar tersebut menunjukkan bahwa tanpa menggunakan flywheel ( 0 rpm) mengakibatkan sudut kemiringan perahu yang paling tinggi dalam pengujian, jika dibandingkan hasil pengujian lainnya yang menggunakan putaran flywheel sebagai menstabil kemiringan perahu. Pada gambar menunjukkan bahwa pada putaran maksimal (500 rpm) menghasilkan kemiringan yang lebih tinggi dibandingkan dengan putaran medium $(2500 \mathrm{rpm})$ hal ini dikarenakan putaran yang tinggi menghasilkan getaran yang tinggi pada struktur perahu sehingga kemiringan perahu menjadi tidak stabil. Hal ini sejalan dengan yang dijelaskan oleh peneliti sebelumnya [15] yang menyatakan bahwa putaran yang teralalu tinggi dapat mengakibatkan material pada flywheel cepat rusak dan tidak stabil. 
Pada Gambar 5 menunjukkan grafik hasil pengujian rerata. Dalam grafik menunjukkan bahwa putaran 0 rpm yang ditunjukkan pada garis berwarna biru kemiringan perahu mencapai paling tinggi diantara hasil pengujian lainnya. Disini menunjukkan pengaruh dari gyroscope stabilizer sebagai alat untuk stabilisasi perahu memberikan hasil yang signifikan dengan memperhatikan putaran (rpm) yang ideal. Pada grafik juga menunjukkan tingginya ombak dapat menghasilkan sudut kemiringan perahu yang dihasilkan. Semakin kecil ombak yang diterima perahu, semakin kecil pula kemiringan perahu yang dihasilkan, begitu pula sebaliknya. Pada hasil optimal putaran 2500 rpm, menunjukkan sudut kemiringan terendah pada ketinggian ombak $3 \mathrm{~cm}$ dan pada ketinggian $5 \mathrm{~cm}$ dan $10 \mathrm{~cm}$ tidak terpaut kemiringan yang terlalu jauh, hal ini menunjukkan penambahan tinggi ombak memberikan penambahan kemiringan yang tidak terlalu besar, dan menunjukkan hasil yang dicapai sudah optimal pada putaran tersebut.

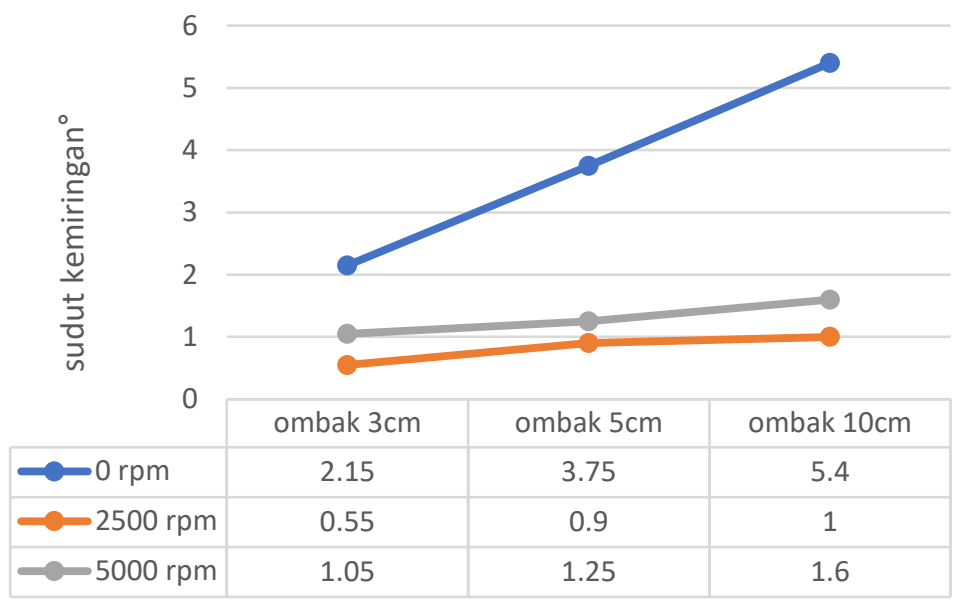

Gambar 5. Grafik rerata sudut kemiringan perahu

\section{Kesimpulan}

Kesimpulan yang dapat diambil dari hasil pengujian yang telah dilakukan, diantaranya yaitu hasil optimal yang diperoleh dari hasil pengujian manunjukkan bahwa gyroscope stabilizer mampu menyeimbangkan sudut kemiringan perahu dengan rentang $0.55^{\circ}$ sampai $1^{\circ}$ dengan kecepatan flywheel $2500 \mathrm{rpm}$, serta perbedaan hasil dari ketinggian ombak $5 \mathrm{~cm}$ dan $10 \mathrm{~cm}$ tidak terpaut jauh, hal ini menunnjukkan hasil optimal sudah dicapai walau diberikan penambahan tinggi ombak. Hasil pengujian menunjukkan bahwa putaran pada flywheel memberikan hasil yang cukup baik dalam mengatasi kemiringan perahu, jika dibandingkan dengan tanpa menggunakan alat ini. Tetapi apabila terlalu tinggi putaran flywheel dapat mengakibatkan tidak stabil dan menyebabkan getaran pada perahu sehingga kemampuan untuk menstabilkan kemiringan perahu menjadi kurang optimal.

\section{Ucapan terima kasih}

Ucapan terima kasih kepada Direktorat Riset dan Pengabdian Masyarakat, Deputi Bidang Penguatan Riset dan Pengembangan, Kementerian Riset, Teknologi / Badan Riset dan Inovasi Nasional atas bantuan hibah Penelitian Dosen Pemula (PDP) untuk pembiayaan penelitian dan publikasi artikel ilmiah ini. Ucapan terima kasih juga kepada Universitas Singaperbangsa Karawang yang telah memfasilitasi dalam penyusunan, pengajuan dan pelaporan hibah Penelitian Dosen Pemula (PDP). 
Deri teguh Santoso dkk /Jurnal Rekayasa Mesin

p-ISSN: 1411-6863, e-ISSN: 2540-7678

Vol.16|No.1|62-68|April|2021

\section{Daftar Pustaka}

[1] Santoso A, Zaman MB. Permesinan bantu pada kapal modern volume 1: permesinan geladak. Airlangga University Press; 2019. p 4.

[2] Jinca, M.Y., Transportasi Laut Indonesia Analisis Sistem dan Studi Kasus. Surabaya: Brilian Internasional; 2011. p 150.

[3] Liputan 6. Kapal Mengangkut 21 Orang Tenggelam di Danau Cirata. https://www.liputan6.com/regional/read 13203853/kapal-mengangkut-21-orang-tenggelam-di-danau-cirata. liputan 6: Regional; 2017 (Diakses pada tanggal 20 Nov 2020).

[4] Fitriadi, N., Saputra, E., Iswantoro, Teknologi terapan perahu fiberglass untuk nelayan sungai kluet kabupaten aceh selatan. Jurnal Cakrawala Maritim. 2018 Agustus; 1(1): p. 1-8.

[5] Mulyadi, M., Yunus, M.Y., Teknologi panel surya perahu nelayan. Seminar Nasional Hasil Penelitian \& Pengabdian Kepada Masyarakat (SNP2M); 2019 Juli. p. 66-69.

[6] Aprianto, R.A., Inovasi teknologi generator listrik independen sebagai sumber energi listrik terbarukan dan penggunaan lampu light emition diode (LED) pada bagan perahu. Hasanuddin Student Journal. 2018 Juni; 2(1): p. $212-216$

[7] Budiharjo, S., Putra, R.S., Rancang bangun model perahu mini robot pembersih sampah di sungai menggunakan android berbasis arduino uno. Journal ICT. 2016; 7(13).

[8] Nugraha, S., Kurniawan, H., Studi kinerja rancang bangun sistem penampil informasi hybrid pada perahu nelayan berbasis google maps. Jurnal Sustainable: Jurnal Hasil Penelitian dan Industri Terapan. 2018 Oktober; 7(2): p. 3945.

[9] Santosa, A.W., Mulyatno. I.P., Pemanfaatan tenaga angin dan surya sebagai alat pembangkit listrik pada bagan perahu. Kapal: Jurnal Ilmu Pengetahuan dan Teknologi Kelautan. 2014 Oktober; 11(3): p. 108-116.

[10] Dewantara, B.Y., Perancangan perahu nelayan ramah lingkungan menggunakan motor listrik bertenaga surya. Cyclotron: Jurnal Teknik Elektro. 2019 Januari ; 2(1).

[11] Norden, C.L., Gyroscope-stabilizer. United States; US 1,236,204. 1917.

[12] Moggo, W.R., Archery bow stabilizer. United States; US 8,220,448. 2012.

[13] Votrubec, R., Stabilization of platform using gyroscope. Procedia Engineering. 2014 Januari; 69: p. 410-414.

[14] Cumbo, H.B., Gyro weapons stabilizer. United States; US 3,165,972. 1965.

[15] Rachmawan, A.P., Ariana, I.M., Gerianto, I., Analisa pengaruh flywheel dan firing order terhadap proses kerja mesin diesel. Jurnal Sistem Perkapalan. 2014; 1(1). p. 1-6 